\title{
Correspondence
}

\section{Lymphangioleiomyoma Cells and Lymphatic Endothelial Cells}

\section{Expression of VEGFR-3 in Lymphangioleiomyoma Cell Clusters}

\section{To the Editor-in-Chief:}

We have read the article by Issaka et al $^{1}$ with great interest as well as deep concern. They reported that lymphangioleiomyoma (LAM) cells express vascular endothelial growth factor (VEGF) receptor (R)-3 and, in turn, that autocrine and paracrine signaling via the VEGF-C/NEGF-D/NEGFR-3 axis plays a role in LAM cell biology in vivo. The source of their LAM-derived cells (LDCs) $)^{2,3}$ was a clone established from LAM nodules in patients' lungs.

We commend the authors' enthusiasm for their results, but have found several inaccuracies. First, although they admit that the LDCs they tested were not LAM cells in vivo, they state in the text as well as the article's title that LAM cells in vivo grow through autocrine cross talk with lymphatic endothelial cells (LECs). Second, they kindly cite our studies reporting that LAM tissues consist of abundant VEGFR-3-positive LECs and that LAM is characterized by an association with lymphangiogenesis. ${ }^{4,5}$ VEGFR-3 is one of the most well-known markers of LECs. ${ }^{6}$ Although we provided concrete evidence that our VEGFR3-positive cells were LECs, we have never stated that LAM cells are VEGFR-3 positive., ${ }^{4,5}$

In Figure 4 of their study, Issaka et al state that LAM cells are positive for VEGFR-3. However, the lung tissues illustrated in Figure 4 do not have VEGFR-3-positiveLECs. Despite the fact that many LAM cells stained positive for VEGFR-3 in this figure, no LECs stained positively for VEGFR-3. We have documented immunostaining of LAM tissue with anti-VEGFR-3 numerous times ${ }^{4,5,7}$ but have never obtained results like those reported by Issaka et al. Our immunostaining in LAM tissues in vivo using the same methods as described previously demonstrates that LECs are positive for VEGFR-3, whereas LAM cells are negative. ${ }^{4,5,7}$ Double immunostaining with $\alpha$-smooth muscle actin (SMA) as a marker of LAM cells and VEGFR-3 as a marker of LEC as well as immunofluorescence using SMA and VEGFR-3 clearly indicate a separation between SMA positive and VEGFR-3 positive cells, with little overlap (unpublished data).
Therefore, we question their use of prox-1 immunostaining to show the existence of LECs in LAM tissue and their claim that perilymphatically-located LAM cells were positive for VEGFR-3. In our hands, double immunostaining for prox-1, a transcription factor specific for LEC, and VEGFR-3 revealed VEGFR-3-positive cytoplasm with prox-1-positive nuclei in only a subset of VEGFR-3 cells (unpublished data). These data suggest that not all LECs are transcriptionally active; that is, some LECs are VEGFR-3-positive but prox-1-negative, whereas some are both VEGFR-3- and prox-1-positive.

When LAM cell clusters (LCCS), isolated from chylous effusion, are cultured, they break into LAM cells and LECs in 5 to 7 days. ${ }^{5}$ Using this model, polygonally shaped LECs are positive for VEGFR-3, whereas spindle-shaped and SMA-positive LAM cells are negative for VEGFR-3 (unpublished data). Importantly, LCCs are genuine LAM cells ${ }^{5,7}$ and differ from LDCs, where clones are isolated from lung tissue after multiple procedural steps and 3 to 10 rounds of passages. ${ }^{1}$ Indeed, LCC-derived cells are maintained in vitro for a very short period and are thus are highly likely to retain the physiological properties of their status in vivo, in contrast to the cloned LDCs that Issaka et al used throughout their experiments. ${ }^{1}$ If the results of the immunohistochemical analysis of LAM tissues (Figure 4, A and B) by Issaka et al were truly correct, we would have to admit that a great difference must exist in the pathogenesis of LAM between the patient populations examined in our studies.

It is now widely accepted that LAM is a neoplastic disease and progresses through metastasis, although LAM cells appear histopathologically benign. However, LAM is a "chronic and slowly progressive neoplasm," leading to destruction of the lungs in a course that is quite distinct from, for example, that of lung cancer, a representative malignant neoplasm of the lungs. Patients with LAM have about a 70\% survival rate at 10 years after diagnosis, ${ }^{8,9}$ which is much longer than that of individuals with lung cancers. Accordingly, LAM patients are candidates for lung transplantation, although LAM can recur in the donor lung. This point seems to have been missed in research on LAM cell biology. LAM cells do not proliferate in vivo as fast as in vitro; therefore, the 
gap between results gained under circumstances most closely duplicating fresh living cells versus those in longerterm culture would be much bigger for LAM cell biology than for cancer cells.

In addition, the precise identity of LAM cells remains unclear. ${ }^{10}$ LAM tissues are composed of heterogeneous cells with different morphologies and immunoreactivities. ${ }^{10}$ Accordingly, the differing appearances of cells in LAM lesions are associated with cell-specific functions, which may help to explain why LAM patients have variable clinical courses. ${ }^{10}$ Conceivably, the clones Issaka et al used may be just one phenotype of LAM cells consisting of LAM lung tissues. However, that type must be a small minority of the overall content in LAM lesions judging from our consecutive results of repeated immunohistochemical analyses. ${ }^{4,5,7}$ From the viewpoint of physician-scientists caring for LAM patients, we believe that LAM researchers must bear in mind whether the choice of cells used in experiments and the role those cells play in vivo are truly relevant for human application.

Kuniaki Seyama Keiko Mitani

Juntendo University School of Medicine

Tokyo, Japan

Toshio Kumasaka

Japanese Red Cross Medical Center

Tokyo, Japan

\section{References}

1. Issaka RB, Oommen S, Gupta SK, Liu G, Myers JL, Ryu JH, Vlahakis NE: Vascular endothelial growth factors $C$ and $D$ induces proliferation of lymphangioleiomyomatosis cells through autocrine crosstalk with endothelium. Am J Pathol 2009, 175:1410-1420

2. Goncharova EA, Goncharov DA, Eszterhas A, Hunter DS, Glassberg MK, Yeung RS, Walker CL, Noonan D, Kwiatkowski DJ, Chou MM, Panettieri RA Jr, Krymskaya VP: Tuberin regulates p70 S6 kinase activation and ribosomal protein S6 phosphorylation. A role for the TSC2 tumor suppressor gene in pulmonary lymphangioleiomyomatosis (LAM). J Biol Chem 2002, 277:30958-30967

3. Goncharova EA, Goncharov DA, Spaits M, Noonan DJ, Talovskaya E, Eszterhas A, Krymskaya VP: Abnormal growth of smooth muscle-like cells in lymphangioleiomyomatosis: role for tumor suppressor TSC2. Am J Respir Cell Mol Biol 2006, 34:561-572

4. Kumasaka T, Seyama K, Mitani K, Sato T, Souma S, Kondo T, Hayashi S, Minami M, Uekusa T, Fukuchi Y, Suda K: Lymphangiogenesis in lymphangioleiomyomatosis: its implication in the progression of lymphangioleiomyomatosis. Am J Surg Pathol 2004, 28:1007-1016

5. Kumasaka T, Seyama K, Mitani K, Souma S, Kashiwagi S, Hebisawa A, Sato T, Kubo H, Gomi K, Shibuya K, Fukuchi Y, Suda K: Lymphangiogenesis-mediated shedding of LAM cell clusters as a mechanism for dissemination in lymphangioleiomyomatosis. Am J Surg Pathol 2005, 29:1356-1366

6. Lohela M, Bry M, Tammela T, Alitalo K: VEGFs and receptors involved in angiogenesis versus lymphangiogenesis. Curr Opin Cell Biol 2009, 21:154-165

7. Mitani K, Kumasaka T, Takemura H, Hayashi T, Gunji Y, Kunogi M, Akiyoshi T, Takahashi K, Suda K, Seyama K: Cytologic, immunocytochemical and ultrastructural characterization of lymphangioleiomyomatosis cell clusters in chylous effusions of patients with lymphangioleiomyomatosis. Acta Cytol 2009, 53:402-409

8. Hayashida M, Seyama K, Inoue Y, Fujimoto K, Kubo K: The epidemiology of lymphangioleiomyomatosis in Japan: a nationwide cross- sectional study of presenting features and prognostic factors. Respirology 2007, 12:523-530

9. Matsui K, Beasley MB, Nelson WK, Barnes PM, Bechtle J, Falk R, Ferrans VJ, Moss J, Travis WD: Prognostic significance of pulmonary lymphangioleiomyomatosis histologic score. Am J Surg Pathol 2001, 25:479-484

10. Finlay G: The LAM cell: what is it, where does it come from, and why does it grow?. Am J Physiol Lung Cell Mol Physiol 2004, 286:L690-L693

\section{Authors' Response:}

We thank Seyama et al for their interest in our recent publication ${ }^{1}$ in the Journal and commend their group on the extensive and important work they have contributed to the field of LAM research. Despite their quite lengthy correspondence regarding our publication, we have identified only two points of concern, which we address in our response below.

Foremost is the apparent discrepancy in the cell-type expression of VEGF-R3. Seyama et al highlight an apparent conflict in findings with their previously published studies $^{2,3}$ and a significant amount of non-peer reviewed work referred to in their letter. The majority of their work is based on immunohistochemistry, a technique that although helpful has significant limitations when trying to draw conclusions on cellular biology. This is in part why we went to great lengths to use an in vitro LAM cell model that was as close to a physiologically relevant model available: cells from human lung LAM nodules. This allowed us to more thoroughly develop an understanding of VEGF/NEGF-R3 biology in LAM that would not be possible with immunohistochemistry alone. Thus, we believe that although the criticisms of our immunohistochemistry findings are reasonable given the apparent difference in findings, by applying the same critical logic Seyama et al have used, their previous work can be as easily called into question.

To address Seyama et al's concern more directly, we found that human LAM nodule cells with an endothelial cell morphology that lined irregularly shaped channels all expressed both Prox-1 and VEGF-R3 and, as such, were clearly identified as LECs. However, the surrounding cells within LAM nodules expressed VEGF-R3 alone without Prox-1 staining. We agree that VEGF-R3 is a well known marker of LECs, however, compared to Prox-1 it is significantly less specific ${ }^{4,5}$ since VEGF-R3 has clearly been shown to be expressed in other cell types, including corneal epithelium, ${ }^{6}$ osteoblasts, ${ }^{7}$ hepatocytes, ${ }^{8}$ and renal podocytes. ${ }^{9}$ Also, in our experience and that of others, including Kumasaka et al, ${ }^{2}$ variability in the pattern of VEGF-R3 expression and lymphangiogenesis in LAM tissues is not uncommon. In fact, this point is well highlighted by Seyama et al in the description of their unpublished work where they report an apparent discrepancy in distribution of Prox-1 and VEGF-R3 expression: a finding consistent with our publication. However, we respectfully disagree with their interpretation that the cells expressing VEGF-R3 without nuclear Prox-1 were "transcriptionally inactive" since expression of Prox-1 is necessary to maintain the lymphatic identity of endothelial cells. ${ }^{5}$ Therefore, our interpretation of those cells expressing VEGF-R3 
without nuclear Prox-1 as LAM cells appears to be quite plausible.

Furthermore, Seyama et al point out that LAM can be considered a "neoplastic process," and we believe the cancer literature contains biological evidence that further supports our findings and the plausibility of an important biological role for VEGF-R3 in LAM. First, cancer cells may demonstrate plasticity resulting in "vasculogenic mimicry."10 In this setting, cancer cells are able to mimic the activities of endothelial cells, resulting in a process similar to neovascularization with the formation of a fluid-conducting, matrix-rich meshwork. Second, VEGFR-3 expression in non-endothelial cells such as corneal epithelium ${ }^{6}$ and osteoblasts ${ }^{7}$ has been implicated in cell differentiation. Third, VEGFR-3 expression has been implicated as a pathogenic factor during hepatocarcinogenesis ${ }^{8}$ and in lung cancers, ${ }^{11,12}$ wherein VEGF-R3 contributes to cell proliferation and migration via autocrine signaling involving VEGF-C/ VEGFR-3.

The second point of concern for Seyama et al addresses the nature of a LAM cell and the biological plausibility of in vitro models in a disease where the pathogenic cell is poorly characterized. This is a key quandary faced by all LAM researchers and has greatly hindered our collective understanding of LAM. As previously stated, we used an in vitro, physiologically relevant LAM cell model $^{13}$ from human lung LAM nodules to more closely study LAM biology in a way that is not possible with immunohistochemistry alone. Seyama et al rightfully highlight the inherent limitations of such cell models; however, we are puzzled by how the authors can then use the data obtained from their own rudimentary in vitro human LAM lung cells ${ }^{3}$ to further question the validity of our findings. In fact, their short term cultures of LAM cell clusters showing co-immunostaining for VEGF-R3 and smooth muscle actin in a subpopulation of peripheral polygonal-shaped cells is not compelling, since morphologically all of the cells looked similar and were not two distinct cell populations. Compared with previously used cells models such as rat renal leiomyoma ${ }^{14}$ cells and fibroblasts, ${ }^{15}$ we believe our use of cells described in numerous high quality publications ${ }^{13,16}$ from different laboratories is a reasonable and biologically pertinent approach. We also believe that if data derived from nonhuman non-LAM tissue can be used to spearhead clinical human trials with sirolimus, ${ }^{17}$ it seems reasonable that cell-based biological findings from our experiments might serve as important clues to find alternative therapeutic targets.

Lastly, we respectfully disagree with Seyama et al's assertion that we interpreted our findings as proof of the extent or importance of LAM/VEGF-R3 functioning in vivo, but rather we clearly suggest that VEGF may play an important role and deserves further in vitro and in vivo study.

The letter from Seyama et al appears overly concerned that their previous results are brought in to question by our findings. Rather we believe that our bodies of work are complimentary and have served to foster healthy debate in a field of research sorely lack- ing in an understanding of biological mechanism and treatment "breakthroughs." We also believe that further studies must focus on developing a more diseaserelevant in vitro cell for detailed study of LAM biology so that we do not have to rely so heavily on immunohistochemistry findings and physiologically less relevant cell types and that real steps should be taken toward assessing the safety and efficacy of an antiVEGF-R3 strategy for treatment of LAM.

Shiv K. Gupta Saji Oommen Gang Liu Jay H. Ryu

Mayo Clinic

Rochester, Minnesota

\section{References}

1. Issaka RB, Oommen S, Gupta SK, Liu G, Myers JL, Ryu JH, Vlahakis NE: Vascular endothelial growth factors $C$ and $D$ induces proliferation of lymphangioleiomyomatosis cells through autocrine crosstalk with endothelium. Am J Pathol 2009, 175:1410-1420

2. Kumasaka T, Seyama K, Mitani K, Sato T, Souma S, Kondo T, Hayashi S, Minami M, Uekusa T, Fukuchi Y, Suda K: Lymphangiogenesis in lymphangioleiomyomatosis: its implication in the progression of lymphangioleiomyomatosis. Am J Surg Pathol 2004, 28:1007-1016

3. Kumasaka T, Seyama K, Mitani K, Souma S, Kashiwagi S, Hebisawa A, Sato T, Kubo H, Gomi K, Shibuya K, Fukuchi Y, Suda K: Lymphangiogenesis-mediated shedding of LAM cell clusters as a mechanism for dissemination in lymphangioleiomyomatosis. Am J Surg Pathol 2005, 29:1356-1366

4. Wilting J, Papoutsi M, Christ B, Nicolaides KH, von Kaisenberg CS Borges J, Stark GB, Alitalo K, Tomarev SI, Niemeyer C, Rössler J: The transcription factor Prox1 is a marker for lymphatic endothelial cells in normal and diseased human tissues. FASEB J 2002, 16:1271-1273

5. Johnson NC, Dillard ME, Baluk P, McDonald DM, Harvey NL, Frase SL, Oliver G: Lymphatic endothelial cell identity is reversible and its maintenance requires Prox1 activity. Genes Dev 2008, 22:3282-3291

6. Cursiefen C, Chen L, Saint-Geniez M, Hamrah P, Jin Y, Rashid S, Pytowski B, Persaud K, Wu Y, Streilein JW, Dana R: Nonvascular VEGF receptor 3 expression by corneal epithelium maintains avascularity and vision. Proc Natl Acad Sci USA 2006, 103:11405-11410

7. Orlandini M, Spreafico A, Bardelli M, Rocchigiani M, Salameh A Nucciotti S, Capperucci C, Frediani B, Oliviero S: Vascular endothelial growth factor-D activates VEGFR-3 expressed in osteoblasts inducing their differentiation. J Biol Chem 2006, 281:17961-17967

8. Lian Z, Liu J, Wu M, Wang HY, Arbuthnot P, Kew M, Feitelson MA Hepatitis Bx antigen up-regulates vascular endothelial growth factor receptor 3 in hepatocarcinogenesis. Hepatology 2007, 45:1390-1399

9. Foster RR, Satchell SC, SeckleyJ, Emmett MS, Joory K, Xing CY Saleem MA, Mathieson PW, Bates DO, Harper SJ: VEGF-C promotes survival in podocytes. Am J Physiol Renal Physiol 2006, 291:F196-F207

10. Hendrix MJ, Seftor EA, Hess AR, Seftor RE: Vasculogenic mimicry and tumour-cell plasticity: lessons from melanoma. Nat Rev Cancer 2003, 3:411-421

11. Su JL, Chen PS, Chien MH, Chen PB, Chen YH, Lai CC, Hung MC Kuo ML: Further evidence for expression and function of the VEGFCNEGFR-3 axis in cancer cells. Cancer Cell 2008, 13:57-60

12. Saintigny $P$, Kambouchner M, Ly M, Gomes N, Sainte-Catherine O, Vassy R, Czernichow S, Letoumelin P, Breau JL, Bernaudin JF, Kraemer M: Vascular endothelial growth factor-C and its receptor VEGFR-3 in non-small-cell lung cancer: concurrent expression in cancer cells from primary tumour and metastatic lymph node. Lung Cancer 2007, 58:205-213

13. Goncharova EA, Goncharov DA, Spaits M, Noonan DJ, Talovskaya E, Eszterhas A, Krymskaya VP: Abnormal growth of smooth muscle-like 
cells in lymphangioleiomyomatosis: role for tumor suppressor TSC2. Am J Respir Cell Mol Biol 2006, 34:561-572

14. Astrinidis A, Cash TP, Hunter DS, Walker CL, Chernoff J, Henske EP: Tuberin, the tuberous sclerosis complex 2 tumor suppressor gene product, regulates Rho activation, cell adhesion and migration. Oncogene 2002, 21:8470-8476

15. Zhe X, Yang Y, Jakkaraju S, Schuger L: Tissue inhibitor of metalloproteinase-3 downregulation in lymphangioleiomyomatosis: potential consequence of abnormal serum response factor expression. Am $J$ Respir Cell Mol Biol 2003, 28:504-511
16. Goncharova EA, Goncharov DA, Eszterhas A, Hunter DS, Glassberg MK, Yeung RS, Walker CL, Noonan D, Kwiatkowski DJ, Chou MM, Panettieri RA Jr, Krymskaya VP: Tuberin regulates p70 S6 kinase activation and ribosomal protein $\mathrm{S} 6$ phosphorylation. A role for the TSC2 tumor suppressor gene in pulmonary lymphangioleiomyomatosis (LAM). J Biol Chem 2002, 277:30958-30967

17. Bissler JJ, McCormack FX, Young LR, Elwing JM, Chuck G, Leonard JM, Schmithorst VJ, Laor T, Brody AS, Bean J, Salisbury S, Franz DN: Sirolimus for Angiomyolipoma in Tuberous Sclerosis Complex or Lymphangioleiomyomatosis. N Engl J Med 2008, 358:140-151 